\title{
Tratamento farmacológico de psicose e agitação em pacientes idosos com demência - Quatro décadas de experiência
}

\author{
Kindermann S.S., Dolder C.R., Bailey A., Katz I.R., Jeste D.V. Pharmacological treatment of psychosis and \\ agitation in elderly patients with dementia - Four decades of experience. Drugs Aging 19(4): 257-76, 2002 \\ Comentado por Mariana Franciosi Tatsch ${ }^{1}$
}

\section{Recebido: 16/6/2003 Aceito: 27/6/2003}

A prevalência de demência em pessoas acima de 65 anos de idade é estimada em 5\% a 15\% e pode chegar a $46 \%$ em pessoas acima de 85 anos. A demência de Alzheimer (DA) é responsável por aproximadamente $60 \%$ dos casos de demência em pessoas acima de 65 anos.

Embora a disfunção cognitiva seja a principal característica das demências, transtornos não cognitivos (agitação, delírio, alucinação etc.) relacionados a essas doenças causam grandes dificuldades no cuidado diário desses pacientes. Os sintomas psicológicos e comportamentais da demência (behavioral and psychological symptoms of dementia - BPSD), como são chamados, são responsáveis por diminuir a qualidade de vida de pacientes e cuidadores, aumentar os custos da doença, institucionalização precoce, bem como aumentar a carga para cuidadores e familiares. É estimado que cerca de $90 \%$ dos pacientes com demência experimentarão algum tipo de BPSD ao longo do curso da doença, e não há, até o momento, nenhum tratamento estandardizado para o tratamento dos BPSD.

Dada a referida importância do tema, Kindermann et al. (2002) realizaram uma metanálise, revisando todas as publicações de estudos entre 1960 e 2000 referentes à eficácia dos tratamentos medicamentosos para psicose, agressão e agitação em idosos com demência. Um total de 48 estudos entrou nesta revisão, com tamanhos de amostras que variaram de 10 a 625 pacientes e tempo de duração do estudo variando de 1 a 52 semanas, com grande diferença, também, nos seus desenhos.

Entre os antipsicóticos típicos, haloperidol foi o mais estudado, tendo sido usado em 20 estudos, com melhoras modestas em psicose e agitação, sendo a taxa média de descontinuação de $16,5 \%$ e os principais efeitos adversos foram sintomas extrapiramidais (SEP) e sedação. Outros antipsicóticos típicos foram usados em 23 estudos, em um total de 13 diferentes antipsicóticos, os quais também foram eficazes. A taxa média de descontinuação foi de $15 \%$, com os mesmos efeitos adversos relacionados ao haloperidol: SEP e sedação.

Antipsicóticos atípicos foram avaliados em dez estudos, nos quais foram eficazes, com média de descontinuação de $23 \%$, sendo os principais efeitos adversos: sedação e SEP.

Estabilizadores do humor foram usados em seis estudos, demonstrando eficácia em agitação, e apresentando como principal efeito colateral a sedação, com exceção da carbamazepina, a qual também causou ataxia nessa população.

Em uma tentativa de unificar os resultados dos estudos, os autores calcularam as taxas de eficácia das medicações usadas em ensaios clínicos, duplo-cegos, controlados por placebo e que claramente relataram suas taxas de melhora. Um total de nove estudos preencheu este critério e a taxa de eficácia dos antipsicóticos foi de $61 \%$ (típicos e atípicos) versus 35\% com placebo. Essas taxas foram similares àquelas achadas em outras revisões, como a de Schneider et al. (1990) e de Lanctot et al. (1998).

Quando se consideram os resultados desses estudos, uma modesta melhora com antipsicóticos é normalmente encontrada, embora nenhum antipsicótico tenha demonstrado eficácia superior aos demais, nessa população. Esses resultados confirmam que essas medicações continuam sendo a primeira escolha no tratamento dos BPSD, com medicações não antipsicóticas sendo reservadas como segunda linha.

\footnotetext{
Endereço para correspondência:

Instituto e Departamento de Psiquiatria da FMUSP

Rua Dr. Ovídio Pires de Campos s/n, São Paulo, SP - CEP 05403-010

E-mail: mtatsch@uol.com.br
}

Médica Psiquiatra, Colaboradora do PROTER, Doutoranda do Instituto de Psiquiatria do HCFMUSP. 
O uso de antipsicóticos em pacientes com demência não deve ser feito sem maiores cuidados, visto que essas medicações possuem uma janela terapêutica estreita nessa população, a qual é especialmente sensível a efeitos colaterais como SEP, discinesia tardia (risco seis vezes maior) e acatisia, ocasionados principalmente pelos agentes convencionais, e hipotensão postural, aumento de peso e sedação, ocasionados também por alguns agentes atípicos além dos convencionais.

O perfil de efeitos colaterais deve guiar a escolha dessas medicações. Em virtude de seu melhor perfil, os antipsicóticos atípicos têm sido preferidos em detrimento dos convencionais. Embora o número de estudos com estas novas medicações ainda seja pequeno, elas parecem ser, no mínimo, tão eficazes quanto os antipsicóticos típicos, porém com uma melhor tolerabilidade por parte do paciente.

Infelizmente, ainda não se tem a resposta para a pergunta: qual é a medicação mais efetiva e segura para o tratamento de psicose e agitação em pessoas idosas com demência? Para se responder a essa pergunta, são necessários estudos clínicos com tamanhos de amostras e tempo de estudo suficientes, além de prospectivos, controlados, comparando as medicações antipsicóticas entre si, a fim de se obterem dados mais fidedignos nessa população especial.

\section{Referências bibliográficas}

Kindermann, S,S.; Dolder, C,R.; Bailey. A.; Katz. I.R.; Jeste. D.V. Pharmacological Treatment of Psychosis and Agitation in Elderly Patients with Dementia - Four Decades of Experience. Drugs and Aging 19(4): 257-76, 2002.

Schneider, L.S.; Pollock, V.E.; Lyness. A.S. A Meta-analysis of Controlled Trials of Neuroleptic Treatment in Dementia. Journal of the American Geriatrics Society 38: 553-63, 1990.

Lanctot, K.L.; Test, T.S.; Mittmann, N. et al. Efficacy and Safety of Neuroleptics in Behavioral Disorders Associated with Dementia. Journal of Clinical Psychiatry 59: 550-61, 1998. 